\title{
A Study on Existing Domestic Water Sanitation Practices in Adilabad District, India
}

\author{
Lalitha $^{1 *}$, R. Neela Rani ${ }^{2}$ and S. Suchirithadevi ${ }^{1}$
}

${ }^{1}$ Department of Home Science Extension and Communication Management, Hyderabad, Professor Jayashankar Telangana State Agricultural University, Andhra Pradesh, India

${ }^{2}$ Department of Foods and Nutrition, Hyderabad, Professor Jayashankar Telangana State Agricultural University, Andhra Pradesh, India

*Corresponding author

\section{Keywords \\ Existing domestic water, Sanitation practices, Adilabad District}

\section{Article Info}

Accepted: 02 May 2018 Available Online: 10 June 2018

\section{A B S T R A C T}

A present study was conducted on profile characteristics of tribal women on domestic water sanitation practices. For the study, based upon the nature of the research problem and objectives of the present study, experimental research design was selected. A total of 90 sample comprising 60 tribal women and 30 grass root level women extension personnel (Anganwadi workers) from three mandals of Adilabad district were selected using random sampling technique. The district of Adilabad was selected purposively as the tribes are densely populated when compared to the other districts of the state. Tribal mandals selected for the study were Rebbena, Tandur and Kerameri. Interview schedule was developed for data collection. Frequencies and percentages were used for data analysis. The results of the study were revealed that the primary water source was hand pump for drinking and household purposes, while pond and tap were secondary water sources which were available within a distance of a kilometer. 46.66 percent of the tribal women expressed that they fetched water more than 5 times a day for drinking and household use from water source, whereas in the case of Anganwadi, more than half of them fetched water less than 3 times a day. For fetching water a great majority of the tribal women and Anganwadi workers waited for less than 15 minutes at the community water source. Seventy per cent of the tribal women were responsible for fetching water (70) in the household and in very negligible (1.7) percent households it was the responsibility of men. $43.33 \%$ of the Anganwadi worker stated that women were main responsible for water fetching while in $10 \%$ of the Anganwadi workers household it was the men's responsibility. All the respondents collect water from the source several times every day and never stored the water for more than a day. A great majority of the tribal women (90\%) and Anganwadi workers (86.6\%) took out water by dipping glass held in hand. Only $15 \%$ of the tribal women and $40 \%$ of the Anganwadi workers had the practice of hand washing before handling water. Among those who practiced hand washing, only 2 tribal women and 7 Anganwadi workers had the practice of hand washing with soap. A great majority (96.6\%) of the tribal women and $83.3 \%$ of the Anganwadi workers had hand washing practice before eating. Fifty percent of the tribal women practicing the indigenous practices like washing hands with ash/soil after defecation. While an equal percentage of the tribal women washed their hands with soap and normal water after defecation. But after defecation all the Anganwadi workers had the practice of hand washing with soap and water. Filtering with cloth /sieve was the common water purification practice observed in the tribal area irrespective of the source of collection. Majority of the tribal women (83.3\%) and Anganwadi workers $(66.6 \%)$ stated that they filtered drinking water using cloth or sieve at collection point in order to filter the solid dust particles. Along with cloth filtration about $44.0 \%$ of the tribal women and $35 \%$ of the Anganwadi workers practice boiling of drinking water. 


\section{Introduction}

The World Health Organization (WHO) defines safe drinking water as, "water that does not represent any significant risk to health over a lifetime of consumption, including different sensitivities that may occur between life stages (World Health Organization, 2008). However for billions of people across the globe, access to safe drinking water is limited. Lack of safe water creates an enormous burden in the form of waterborne illnesses such as diarrheal disease, cholera, typhoid etc. Diarrhea and water-borne diseases are leading causes of mortality and morbidity in developing countries.

Safe water is one of the most important felt needs in public health in developing countries in the twenty first century. The year 2005 marked the beginning of the "International Decade for Action: Water for Life" and renewed effort to achieve the Millennium Development Goal (MDG) to reduce by half the proportion of the world's population without sustainable access to safe drinking water and sanitation by 2015. It is estimated by World Health Organization (WHO) and United Nations International Children's Emergency Fund (UNICEF) that 1.1 billion people lack access to improved water supplies and 2.6 billion people lack adequate sanitation

Water has direct impact on health and economic status and effective water sanitation is crucial in view of the depletion of world's safe water and increased health burden of unsafe water. In India, over a billion people lack safe water, 80 per cent of the infection diseases are water borne, killing 1.5 millions of children each year. Approximately 88 per cent of diarrheal diseases are attributed to unsafe water supply, inadequate sanitation and hygiene (WHO, 2004). The proportion of population in rural areas with access to safe drinking water has a direct impact on the health of the masses. Water sources and sanitation facilities have an important influence on the health of household members, especially children. The intensity of the water related health problems is very high in tribal habitations compared to rural and urban.

Bharti et al., (2013) in their study revealed that all informants perceived about importance of covered drinking water in prevention of diseases but covered drinking water was found in $96.8 \%$ of households and stored in earthen pots $(92.5 \%)$. Around two third of informants (64.4\%) did not know about importance of ladle to draw water while ladle was actually being used in less than one third $(30.5 \%)$ of households only.

Busenna and Snehalatha (2013) conducted a study in Kurnool district to assess water, sanitation and hygienic practices in rural India and results indicated that nearly $98 \%$ of the women were washing hands after defecation and before and after eating of food while only $2 \%$ of the households did not washing hands with soap after defecation. With reference to caste, $63.8 \%$ of SCs are washing hands without using any material, followed by STs (57.1\%), BCs $(48.9 \%)$ and OCs $(27.3 \%) .50 \%$ of STs and their children are not washing hands before and after food, followed by BCs (30.7\%), OCs (29.4\%) and SCs (20.5\%). Nearly, $43 \%$ children are using soap for washing hands before and after food. Majority of the households are far away for tap connection and toilet access in general and particularly in SCs and STs.

Bharti et al., (2013) in their study revealed that all informants perceived about importance of covered drinking water in prevention of diseases but covered drinking water was found in $96.8 \%$ of households and stored in earthen pots $(92.5 \%)$. Around two third of informants (64.4\%) did not know about importance of ladle to draw water while ladle was actually 
being used in less than one third (30.5\%) of households only.

Mishra and Nandeshwar (2013) in their study revealed that the only water purification method known and practiced in the selected village was filtration by cloth or plastic sieve. Only 99 (31.7\%) families reported of washing hands always, $175(56.09 \%)$ sometimes and 38 (12.2\%) families never wash their hands before drawing water from the vessels.

\section{Materials and Methods}

For the study, based upon the nature of the research problem and objectives of the present study, experimental research design was selected.

A total of 90 sample comprising 60 tribal women and 30 grass root level women extension personnel (Anganwadi workers) from three mandals of Adilabad district were selected using random sampling technique.

The district of Adilabad was selected purposively as the tribes are densely populated when compared to the other districts of the state. The high incidence of mortality and morbidity among tribals due to unsafe drinking water is also an important factor which led to the selection of this particular location. Tribal mandals selected for the study were Rebbena, Tandur and Kerameri.

Variables selected for the study on existing domestic water sanitation practices: water collection practices, water storage practices, water handling practices, water and hygiene practices, water purification practices. Interview schedule was developed for the study to gather the information from the respondents.

Frequency was used to know the distribution pattern of the respondents according to the variables. Percentages were used for standardization of size by calculating the number of individuals that would be in a given category if the total number of cases were 100 .

\section{Results and Discussion}

The results of the present study was presented below

Existing domestic water sanitation practices: the variables like water collection practices, water storage practices, water handling practices, water and hygiene practices, water purification practices the following tables present the existing domestic water sanitation practices data of the respondents.

\section{Water collection}

It is clear from the table 1 that all the tribal women and Anganwadi workers expressed that hand pump was the primary source of water for drinking and household purpose. While $33.33 \%$ of the tribal women and $36.66 \%$ of Anganwadi workers stated pond as secondary water source for drinking.

Twenty percent of the tribal women and 46.66 percent of the Anganwadi workers used tap as the secondary source of water for household purpose. This might be due to the fact that the above respondents had household tap connection for which they were paying Rs.30 per month and they preferred to use tap water for the household purposes.

The findings were in line with the results reported by Ministry of tribal affairs (2013).

It was apparent from the table 2 With regard to frequency of water fetching, nearly half of the tribal women expressed that they fetch water more than 5 times a day for drinking and household use from water source followed by 3 to 5 times (33.33\%) and less than 3 times 
(20\%) a day. The reason for fetching water more than 5 times a day might be because of their family size and lack of household tap connection. It was also observed from the study area that majority of the tribal women depended on hand pump for drinking and household purposes.

Whereas in the case of Anganwadi workers, more than half of them fetch water less than 3 times a day from water source followed by 3-5 times a day (26.66\%) and more than 5 times $(20.00 \%)$ a day. The reason for low frequency of water fetching i.e. less than 3 times a day among them might be due to their regular income which made them to possess household water tap connection.

It was apparent from the table 2 that a great majority $(78.33 \%)$ of the tribal women expressed that the frequency of waiting for water fetching was "sometimes" followed by "Always" (13.33 \%) and "never" (8.33\%). The reason for waiting might be that in tribal and rural areas usually they collect water in the morning and evening. Rush was observed in the study area in the mornings and evenings because of the existence of less number of community hand pumps in their villages.

It was also evident from the table 2 that a great majority of the tribal women $(91.66 \%)$ and Anganwadi workers (83.33\%) used to wait for less than 15 minutes for fetching the water from the community water source. Very meager percent of the respondents expressed that they waited more than 15 minutes to fetch water at the water source.

As per the table 3 seventy per cent of the tribal women were responsible for fetching water $(70.00 \%)$ in their households fallowed by adolescent girls $(20.00 \%)$ and adolescent boys $(8.33 \%)$. It was also observed from the table that very negligible (1.66\%) percent households it was the responsibility of men.
Table 2 also revealed that $43.33 \%$ of the Anganwadi workers households, women were responsible for water fetching followed by adolescent girls $(26.66 \%)$, adolescent boys $(20.00 \%)$ and men $(10.00 \%)$. There is a little change in the role of men in Anganwadi workers households. Because of the nature of work and busy schedule of the working women, men took responsibility of fetching water in the households of Anganwadi workers.

The above results once again proved gender disparity in performing household chores like fetching water, washing clothes etc., where women were expected to perform and largely responsible for most of the household activities. But education and awareness makes a difference in gender roles. The results were in line with Mishra and Nandeshwar (2013) and Joshi et al., (2014).

\section{Water storage}

As per the table 3 majority of the tribal women $(80.00 \%)$ in this study stored drinking water in steel containers with lid followed by mud pot with lid $(20.00 \%)$. Similarly great majority of the Anganwadi workers (86.66\%) stored drinking water in steel containers with lid followed by mud pot with lid (13.33\%). Covering the vessel with a tight fitting lid is of important to prevent contamination of the water. Contamination of water quickly increases when the water is stored in a vessel without any lid. Majority of women did fetch and stored the drinking water in the same vessel.

The second most common container for storage mainly for household use was plastic containers like buckets, cans, and bottles. The results in the table also revealed that $45.00 \%$ of the tribal women and fifty percent of the Anganwadi workers used plastic containers for storing water for the household use. 
Table.1 Distribution of respondents based on the water sources

\begin{tabular}{|l|l|c|c|c|c|}
\hline S. No. & \multicolumn{1}{|c|}{ Particulars } & \multicolumn{2}{|c|}{ Tribal women (N=60) } & Anganwadi workers (N=30) \\
\hline & Frequency & $\begin{array}{c}\text { Percentage } \\
\mathbf{( \% )}\end{array}$ & Frequency & $\begin{array}{c}\text { Percentage } \\
(\mathbf{\%})\end{array}$ \\
\hline Water sources & & & & \\
\hline 1. & Drinking purpose & & & & \\
\hline & Primary- Hand pump & 60 & 100 & 30 & 100 \\
\hline & Secondary- pond & 20 & 33.33 & 11 & 36.66 \\
\hline 2. & Household purpose & & & & \\
\hline & Primary- Hand pump & 60 & 100 & 30 & 30.00 \\
\hline & Secondary- Tap & 12 & 20.00 & 14 & 46.66 \\
\hline
\end{tabular}

Table.2 Distribution of respondents based on the water fetching practices

\begin{tabular}{|c|c|c|c|c|c|}
\hline \multirow[t]{2}{*}{ S. No. } & \multirow[t]{2}{*}{ Particulars } & \multicolumn{2}{|c|}{ Tribal women $(\mathrm{N}=60)$} & \multicolumn{2}{|c|}{ Anganwadi workers $(\mathrm{N}=\mathbf{3 0})$} \\
\hline & & $\begin{array}{c}\text { Frequenc } \\
\mathbf{y}\end{array}$ & $\begin{array}{c}\text { Percentage } \\
(\%)\end{array}$ & Frequency & $\begin{array}{l}\text { Percentage } \\
\text { (\%) }\end{array}$ \\
\hline \multicolumn{6}{|c|}{ Frequency of fetching water } \\
\hline & Less than 3 times & 12 & 20.00 & 16 & 53.33 \\
\hline & $3-5$ times & 20 & 33.33 & 8 & 26.66 \\
\hline & More than 5 times & 28 & 46.66 & 6 & 20.00 \\
\hline & Total & 60 & 100 & 30 & 100 \\
\hline \multicolumn{6}{|c|}{ Frequency of waiting } \\
\hline & Always & 8 & 13.33 & 6 & 20.00 \\
\hline & Some times & 47 & 78.33 & 5 & 16.66 \\
\hline & Never & 5 & 8.33 & 19 & 63.33 \\
\hline & Total & 60 & 100 & 30 & 100 \\
\hline \multicolumn{6}{|c|}{ Waiting time } \\
\hline & Less than 15 minutes & 55 & 91.66 & 25 & 83.33 \\
\hline & Above 15 minutes & 5 & 8.33 & 5 & 16.66 \\
\hline & Total & 60 & 100 & 30 & 100 \\
\hline
\end{tabular}

Table.3 Distribution of respondents based on the gender role in water fetching

\begin{tabular}{|l|l|c|c|c|c|}
\hline S. No. & \multicolumn{1}{|c|}{ Particulars } & \multicolumn{2}{c|}{ Tribal women $(\mathbf{N = 6 0 )}$} & \multicolumn{2}{c|}{ Anganwadi workers (N=30) } \\
\hline & Gender role & $\begin{array}{c}\text { Frequen } \\
\text { cy }\end{array}$ & $\begin{array}{c}\text { Percentage } \\
(\mathbf{\%})\end{array}$ & Frequency & Percentage (\%) \\
\hline 1. & Women & 42 & 70.00 & 13 & 43.33 \\
\hline 2. & Adolescent girls & 12 & 20.00 & 8 & 26.66 \\
\hline 3. & Adolescent boys & 5 & 8.33 & 6 & 20.00 \\
\hline 4. & Men & 1 & 1.66 & 3 & 10.00 \\
\hline
\end{tabular}




\begin{tabular}{|c|c|c|c|c|c|}
\hline S. No. & Particulars & \multicolumn{2}{|c|}{ Tribal women $(\mathrm{N}=60)$} & \multicolumn{2}{|c|}{ Anganwadi workers (N=30) } \\
\hline \multirow{6}{*}{1.} & \multicolumn{5}{|l|}{ Water storage container } \\
\hline & \multicolumn{5}{|l|}{ Drinking purpose } \\
\hline & Steel with lid & 48 & 80.00 & 26 & 86.66 \\
\hline & Mud pot with lid & 12 & 20.00 & 4 & 13.33 \\
\hline & \multicolumn{5}{|l|}{ Household purpose } \\
\hline & Plastic & 27 & 45.00 & 15 & 50.00 \\
\hline \multirow[t]{3}{*}{2.} & \multicolumn{5}{|c|}{ Drinking water storage duration } \\
\hline & 1 day & 60 & 100 & 30 & 100 \\
\hline & 2 days & 20 & 33.33 & 8 & 26.66 \\
\hline \multirow[t]{4}{*}{3.} & \multicolumn{5}{|l|}{ Storage vessel cleaning } \\
\hline & Daily & 39 & 65.00 & 22 & 73.33 \\
\hline & Once in two days & 13 & 21.66 & 8 & 26.66 \\
\hline & Once in three days & 8 & 13.33 & 0 & 0.00 \\
\hline
\end{tabular}

\begin{tabular}{|c|c|c|c|c|c|}
\hline \multirow{2}{*}{$\begin{array}{l}\text { S. No. } \\
1 . \\
\end{array}$} & \multirow{2}{*}{$\begin{array}{l}\text { Particulars } \\
\text { Handling Water }\end{array}$} & \multicolumn{2}{|c|}{ Tribal women $(\mathrm{N}=\mathbf{6 0})$} & \multicolumn{2}{|c|}{ Anganwadi workers (N=30) } \\
\hline & & Frequency & Percentage $(\%)$ & Frequency & Percentage $(\%)$ \\
\hline & Dipping glass /tumbler with hand & 54 & 90.00 & 26 & 86.66 \\
\hline & Using handled donga & 4 & 6.66 & 0 & 0.00 \\
\hline & Using mud pot with tap & 2 & 3.33 & 4 & 13.33 \\
\hline \multicolumn{2}{|r|}{ Total } & 60 & 100 & 30 & 100 \\
\hline \multirow[t]{4}{*}{2.} & \multicolumn{5}{|c|}{ Washing hand before handling water } \\
\hline & \multirow{3}{*}{$\begin{array}{l}\text { Yes } \\
\text { No }\end{array}$} & 9 & 15.00 & 12 & 40.00 \\
\hline & & 51 & 85.00 & 18 & 60.00 \\
\hline & & 60 & 100 & 30 & 100 \\
\hline \multirow[t]{5}{*}{3.} & \multicolumn{5}{|l|}{ Material used for hand washing } \\
\hline & With water only & 58 & 96.66 & 23 & 76.66 \\
\hline & With soap and water & 2 & 3.33 & 7 & 23.33 \\
\hline & Ash/Soil and water & 0 & 0.00 & 0 & 0.00 \\
\hline & Total & 60 & 100 & 30 & 100 \\
\hline
\end{tabular}

\section{Table.6 Distribution of the respondents based on their water and hygiene practices}

\begin{tabular}{|c|c|c|c|c|c|}
\hline S. No. & Particulars & \multicolumn{2}{|c|}{ Tribal women $(\mathrm{N}=60)$} & \multicolumn{2}{|c|}{ Anganwadi workers $(\mathrm{N}=30)$} \\
\hline 1. & Washing hands before eating food & Frequency & Percentage (\%) & Frequency & Percentage (\%) \\
\hline & With water only & 58 & 96.66 & 25 & 83.33 \\
\hline & With soap and water & 2 & 3.33 & 5 & 16.66 \\
\hline & Ash/Soil and water & 0 & 0.00 & 0 & 0.00 \\
\hline & Total & 60 & 100 & 30 & 100 \\
\hline 2. & Washing hands after defecation & & & & \\
\hline & With water only & 15 & 25.00 & 0 & 0.00 \\
\hline & With soap and water & 15 & 25.00 & 30 & 100 \\
\hline & Ash/Soil and water & 30 & 50.00 & 0 & 0.00 \\
\hline & Total & 60 & 100 & 30 & 100 \\
\hline 3. & Disposal of waste water & & & & \\
\hline & Open drain & 55 & 91.66 & 26 & 86.66 \\
\hline & Close drain & 0 & 0.00 & 0 & 0.00 \\
\hline & Any other & 5 & 8.33 & 5 & 16.66 \\
\hline & Total & 60 & 100 & 30 & 100 \\
\hline
\end{tabular}


Table.7 Distribution of the respondents based on their water purification methods

\begin{tabular}{|c|c|c|c|c|c|}
\hline \multirow{2}{*}{ S. No. } & \multirow[t]{2}{*}{ Particulars } & \multicolumn{2}{|c|}{ Tribal women $(\mathrm{N}=60)$} & \multicolumn{2}{|c|}{ Anganwadi workers ( $\mathrm{N}=30$ ) } \\
\hline & & Frequency & Percentage (\%) & Frequency & Percentage $(\%)$ \\
\hline 1. & No purification & 10 & 16.66 & 10 & 33.33 \\
\hline 2. & $\begin{array}{l}\text { Filtering with cloth } \\
\text { /sieve }\end{array}$ & 50 & 83.33 & 20 & 66.66 \\
\hline & Total & 60 & 100 & 30 & 100 \\
\hline & $\begin{array}{l}\text { Filtering with cloth and } \\
\text { Boiling }\end{array}$ & 22 & 44.00 & 7 & 35.00 \\
\hline & $\begin{array}{l}\text { Filtering with cloth and } \\
\text { water Filter device }\end{array}$ & 2 & 4.00 & 4 & 20.00 \\
\hline & $\begin{array}{l}\text { Filtering with cloth and } \\
\text { using chlorine tablets }\end{array}$ & 17 & 34.00 & 7 & 35.00 \\
\hline
\end{tabular}

Of the remaining $55.00 \%$ of the tribal women and fifty per cent of the Anganwadi workers fetch water then and there whenever they required. With regard to the drinking water storage duration, all the respondents including tribal women and Anganwadi workers did fetch water several times every day and never stored the water for more than a day. On the other hand $33.33 \%$ of the tribal women and $26.66 \%$ of the Anganwadi workers stated that during the dry season they do stored the water for two days.

About $65 \%$ of tribal women and $73.33 \%$ of Anganwadi workers had the practice of cleaning their drinking water container daily. This might be due to reason that they collected water frequently from water source which is very nearer to their households. It is also observed from the study area that tribal respondents used ash or soil for cleaning the water storage containers. The remaining $21.66 \%$ of tribal women and $26.66 \%$ of Anganwadi workers cleaned their drinking water containers once in 2 days. Very few tribal women had the practice of cleaning water storage containers once in three days.

\section{Water handling}

It was clear from the table 5 that only 3.33 per cent of tribal women and $13.33 \%$ of the Anganwadi workers used mud pot with tap and 6.66per cent of the tribal women used handled jug for taking out the drinking water from the container. A great majority of the tribal women (90.00\%) and Anganwadi workers (86.66\%) had the practice of taking out drinking water by dipping glass/tumbler held in hand. With regard to hand washing practice before handling water, a small percentage of the tribal women $(15.00 \%)$ and $(40.00 \%)$ of the Anganwadi workers had the practice of hand washing. While a great majority $(85.00 \%)$ of the tribal women and sixty percent of the Anganwadi workers did not wash their hands before handling drinking water. Among those who practice hand washing, only two tribal women and seven Anganwadi workers had the practice of washing hands with soap.

Similar results were found in Bhattacharya et al., (2011) where only 38\% of households used handled jug to take out drinking water from water container and most of the respondents interviewed took out water by dipping glass held in hand without washing their hands. This practice of handling water increases the risk of microbial contamination of drinking water by contact with potentially contaminated hands.

World health organization (2009) also stated that washing hands with soap has been found to reduce water borne diseases by approximately 23 percent and estimated 297,000 people die every year from preventable cases of diarrhea caused by inadequate hand hygiene. Hence there is a huge need to educate and empower tribal and rural community regarding the water related sanitation practices. 


\section{Water and hygiene practices}

On assessing the practices related to water and hygiene, it was evident from the table 6 that a great majority $(96.66 \%)$ of the tribal women washed hands with water only followed by with soap and water $(3.33 \%)$ before eating. More than fifty percent of the tribal women were still practicing the indigenous method like washing hands with ash/soil after defecation. While an equal percentage of the tribal women washed their hands with soap and water $(25.00 \%)$ and with water only $(25.00 \%)$ after defecation.

Whereas in case of Anganwadi workers, majority $(83.33 \%)$ of them washed their hands with normal water followed by soap and water $(16.66 \%)$ before eating. But after defecation all the Anganwadi workers had the practice of hand washing with soap and water. The reason for this practice might be due to their education level and area of work. With regard to disposal of waste water, majority of the tribal women (91.66\%) and Anganwadi workers (86.66\%) disposed waste water in an open drains followed by other practices like disposal at backyard garden. Disposal of waste water in front of their houses leads to potential breeding ground for mosquitoes which also cause airborne diseases.

\section{Water purification}

From the table 7 it was evident that all respondents had access to community water source like hand pump. The water quality was probably improved compared to other surface sources like canal, river etc. However, it is important to remember that even if the water quality was improved, there are a lot of other factors that have to be taken into consideration to make sure that the water is safe for drinking.

The tribal women were asked how they purify water before drinking, to this majority of the tribal women $(83.33 \%)$ stated that they filtered their drinking water using cloth or sieve at collection point in order to filter the solid dust particles. Along with cloth filtration about
$44.00 \%$ of the tribal women practice boiling of drinking water followed by using chlorine tablets $(34.00 \%)$ and use of water filter device $(4.00 \%)$.

With regard to Anganwadi workers, majority of them $(66.66 \%)$ stated that they filtered their drinking water using cloth or sieve. Along with cloth filtration about $35.00 \%$ of the Anganwadi workers practice boiling of drinking water followed by using chlorine tablets $(35.00 \%)$ and use of water filter device $(20.00 \%)$.

Filtering with cloth/sieve was the common water purification practice observed in the tribal area irrespective of the source of collection. They expressed the reason for purifying the water is mainly to prevent diarrhea.

The results were in line with Bharti et al., (2013).

From the study, it was concluded that the primary water source was hand pump for drinking and household purposes, while pond and tap were secondary water sources which were available within a distance of a kilometer. 46.66 percent of the tribal women expressed that they fetched water more than 5 times a day for drinking and household use from water source, whereas in the case of Anganwadi, more than half of them fetched water less than 3 times a day. For fetching water a great majority of the tribal women and Anganwadi workers waited for less than 15 minutes at the community water source. Seventy per cent of the tribal women were responsible for fetching water (70) in the household and in very negligible (1.7) percent households it was the responsibility of men. $43.33 \%$ of the Anganwadi worker stated that women were main responsible for water fetching while in $10 \%$ of the Anganwadi workers household it was the men's responsibility.

All the respondents collect water from the source several times every day and never stored the water for more than a day. A great majority of the tribal women (90\%) and Anganwadi 
workers $(86.6 \%)$ took out water by dipping glass held in hand. Only $15 \%$ of the tribal women and $40 \%$ of the Anganwadi workers had the practice of hand washing before handling water. Among those who practiced hand washing, only 2 tribal women and 7 Anganwadi workers had the practice of hand washing with soap.

A great majority $(96.6 \%)$ of the tribal women and $83.3 \%$ of the Anganwadi workers had hand washing practice before eating. Fifty percent of the tribal women practicing the indigenous practices like washing hands with ash/soil after defecation. While an equal percentage of the tribal women washed their hands with soap and normal water after defecation. But after defecation all the Anganwadi workers had the practice of hand washing with soap and water.

Filtering with cloth /sieve was the common water purification practice observed in the tribal area irrespective of the source of collection. Majority of the tribal women $(83.3 \%)$ and Anganwadi workers (66.6\%) stated that they filtered drinking water using cloth or sieve at collection point in order to filter the solid dust particles. Along with cloth filteration about $44.0 \%$ of the tribal women and $35 \%$ of the Anganwadi workers practice boiling of drinking water.

\section{References}

Bharti, M. M., Kumar, V., Verma, R., Chawla, S. and Sachdeva, S. 2013. Knowledge Attitude and Practices Regarding Water Handling and Water Quality Assessment in a Rural Block of Haryana.
International Journal of Basic and Applied Medical Sciences. 3 (2). 243-247. Bhattacharya, M., Joon, V. and Jaiswal, V. 2011. Water Handling and Sanitation Practices in Rural Community of Madhya Pradesh: a knowledge, attitude and practice study. Indian Journal of Preventive and Social Medicine.42 (1): 93-97

Busenna, P. and Snehalatha, M. 2013. Water, Sanitation and Hygienic Practices in Rural India: A Case Study of Gargeyapuram Village, Kurnool District of Andhra Pradesh. Journal of Governance \& Public Policy. 3(1): 1-8.

Joshi, A., Prasad, S., Kasav, J., Segan, M. and Singh, A. 2014. Water and Sanitation Hygiene Knowledge Attitude Practice in Urban Slum Settings. Global Journal of Health Science. 6 (2): 23-34.

Ministry of tribal affairs.2013. Statistical profile of scheduled tribes in India 2013; Statistics division Government of India.

Mishra, S. and Nandeshwar, S. 2013. A Study to assess Water source Sanitation, Water Quality and Water Related Practices at Household level in Rural Madhya Pradesh. National Journal of Community Medicine. 4 (4): 599-602.

World health organization (WHO). 2004. Report on unsafe water supply, inadequate sanitation and hygiene.

World health organization (WHO). 2008. Report on Guidance on communication with respect to safe drinking water and household hygiene.

World health organization (WHO). 2009. Report on water and sanitation in India.

\section{How to cite this article:}

Lalitha, R. Neela Rani and Suchirithadevi, S. 2018. A Study on Existing Domestic Water Sanitation Practices in Adilabad District, India. Int.J.Curr.Microbiol.App.Sci. 7(06): 22-30. doi: https://doi.org/10.20546/ijcmas.2018.706.004 